\title{
Educação física, linguagem e arte: possibilidades de um diálogo poético do corpo
}

Carmen Lúcia Soares* José Rafael Madureira**

\begin{abstract}
Resumo: É possível pensar numa composição entre Educação Física, linguagem e arte? A incorporação da arte nas reflexões concernentes à Educação Física poderia auxiliar na configuração de uma outra lógica para pensar o corpo e todos os fenômenos a ele ligados, inclusive no que diz respeito a sua expressão gestual. Neste artigo, apresentamos algumas discussões que apontam para a historicidade desta relação, tomando por base os estudos de Noverre, Delsarte e Dalcroze.

Palavras-chave: educação, linguagem, arte, educação física, corpo, expressão.
\end{abstract}

\section{O que é a arte?}

A arte é um aglomerado de ciência, magia e técnica, uma janela para o conhecimento sensível do mundo. Em sua polissemia ela revela a diversidade de corpos, suas singularidades, sendo avessa a resultados orientados pela medida e pela utilidade. O artista traduz o mundo sensível e imaterial em formas, sabores, cores, texturas, volumes e odores. A arte é capaz de extrair formas outras daquilo que se mostra aparente, de mergulhar no que é mais desconhecido, de romper a mera percepção e de considerar a imaginação como capacidade humana para a criação. Nas palavras extraídas do filme de Federico Fellini: "Nada se sabe, tudo se imagina" (A voz da lua, 1990).

A arte é sempre uma expressão do corpo. Sua matéria, seu ponto de partida e de chegada é sempre o corpo. Às vezes a matéria-corpo aparece de forma oculta, traduzida em tintas, palavras ou acordes musicais. Ainda assim, é a experiência humana encarnada que se revela em terrores e júbilos. É preciso que o espírito do artista repouse sobre a matéria, sobre as ferramentas e suas tecnologias. Argila e escultor precisam compor um único pensamento, uma única vontade. A matéria transformada

* Doutora em Educação e Professora da Faculdade de Educação Física da UNICAMP

** Mestre em Educação e Doutorando em Educação pela UNICAMP

Movimento, Porto Alegre, v. 11, n. 2, p.75-88, maio/agosto de 2005 
reflete as metamorfoses interiores do próprio artista como num processo alquímico: a obra nada mais é do que a materialização simbólica das transformações interiores do alquimista. O poeta, assim como o pintor ou mesmo o musicista, constrange o próprio corpo para expressar e imprimir em uma matéria exterior a si - ao seu corpo - algo que possa ser visto e apreciado por outros. E "o que é a arte pura segundo a concepção moderna? É criar uma magia sugestiva contendo ao mesmo tempo o objeto e o sujeito, o mundo exterior ao artista e o próprio artista" (Baudelaire, 1991, p. 71).

As artes dramáticas revelam-se numa lógica particular, configuram-se em idiossincrasias próprias. Somos levados a pensar na dança e no teatro como experiências poéticas nas quais artista e obra se encontram de antemão organicamente fundidos. A expressão de seu fazer poético está no corpo, é o próprio corpo do artista e não existirá mais quando o espetáculo for concluído, pois são artes do instante, artes da oralidade que vivem apenas no momento de sua aparição poética. (Evidentemente os espetáculos podem ser filmados ou fotografados, mas nesse caso já não teremos o corpo do intérprete, mas uma representação, uma tradução de uma linguagem em outra).

A arte sempre educou as sociedades em todos os tempos. A dança, a música e a linguagem pictórica eram os espaços freqüentados por todos. Foi trabalhando, conversando, festejando, cantando, ouvindo, olhando e dançando que as sociedades do mundo, em grande parte iletradas, puderam humanizar-se.

[...] a educação que um menino recebe dos objetos, das coisas, da realidade física - em outras palavras, dos fenômenos materiais da sua condição social-, tornao corporalmente aquilo que é e será por toda a vida. O que é educada é a sua carne, como forma do seu espírito. A condição social se reconhece na carne de um indivíduo. Porque ele foi fisicamente plasmado justamente pela educação física da matéria da qual é feito o mundo (Pasolini, 1990, p. 127).

Cada objeto contemplado, cada grande nome murmurado éo ponto de partida de um sonho e de um verso, é um movimento lingüístico criador. Quantas vezes, à beira do poço, sobre a velha pedra coberta de azedas bravas e de fetos, murmurei o nome das águas longínquas, o nome do mundo sepultado... Quantas vezes o universo me respondeu repentinamente... Ó meus objetos! como conversamos! (Bachelard, 1990, p. 5).

Toda obra de arte é sempre um processo inacabado, um eterno vir-a-ser, uma obra aberta. O artista deforma a realidade transmutando-a em artifícios que desestruturam a fixidez das sociedades e desintegram o pensamento reto e que se quer único. Como então pensar na expressão poética de um corpo minuciosamente vigiado e mudo?

Movimento, Porto Alegre, v. 11, n. 2, p.75-88, maio/agosto de 2005 


\section{A ginástica e a expressão poética do corpo: Delsarte, Noverre e Dalcroze}

Lembremo-nos que a identidade da ginástica científica oitocentista foi estruturada em finalidades úteis do trabalho corporal e no uso "racional" e comedido das forças físicas, não podendo ser associada aos encantos, brilhos e desfigurações das artes dramáticas. Ironicamente, a ginástica científica foi constituída a partir de modos, gestos e técnicas retirados das artes circenses. A brutal ruptura feita com o circo nos ilumina. O circo é um universo no qual o corpo colocado como centro do espetáculo, rompe com supostos limites físicos e morais, reordenando formas e hierarquias, invertendo lógicas e pensamentos, revelando os ruídos obscuros que murmuram sob os pés do artista.

Mas não foi apenas do circo que a ginástica científica se distanciou para criar identidade e se diluir no meio da higiene e da medicina. Ela também desfez os laços que a ligavam ao teatro e à música, tornando-se, de uma certa forma, uma atividade estéril.

A história recente da Educação Física, especialmente nos dois últimos séculos, é farta em fontes documentais, imagéticas ou não, que traduzem de um modo bastante explícito uma relação existente entre a então denominada Ginástica com movimentos artísticos de diferentes expressões desde o teatro, a dança, as artes plásticas, passando também pela música. Sempre presentes, porém nunca hegemônicos, e, menos ainda, modelares para a educação do corpo, as representações da arte ocuparam os espaços fora das margens dos desenhos retos, das atitudes virtuosas, da gestualidade útil. Pensemos nas resistências oferecidas pela Ginástica Harmônica de Steele MacKaye (18421894), pela Rítmica de Emile-Jacques Dalcroze (1865-1950) ou pela Ginástica Expressiva de Rudolf Bode (1881-1971), movimentos fortemente inspirados no pensamento de François Delsarte (1811-1871), ${ }^{1}$ cujos princípios apontavam para um fazer poético e expressivo do corpo.

1 François Delsarte (1811-1871) nasceu em Solesmes, em um pequeno vilarejo ao norte da França. Seguiu, com a idade de 14 anos, para a capital, onde pôde aprofundar seus estudos de canto na Escola Real de Música e Declamação de Paris. Devido a uma condução irresponsável de seu talento, o jovem virtuose foi obrigado a encerrar prematuramente uma carreira inquestionavelmente brilhante, uma vez que teve sua voz, instrumento primeiro de seu trabalho, completamente danificada. Desde então, dedicou-se à fundamentação de um pensamento

Movimento, Porto Alegre, v. 11, n. 2, p.75-88, maio/agosto de 2005 
Eu trago para a vossa apreciação um objeto que é o mais elevado de todas as ciências. Ele é mais belo que as esculturas de Phidias. Ele encerra mais harmonia do que todas as obras de Beethoven, de Mozart emais poesia do que já foi revelada pelos maiores poetas do mundo. Enfim, todas as concepções reunidas do gênio humano desaparecem como sombras diante desta obra suprema. Trata-se, caros senhores, da obra-prima de Deus, trata-se de vós mesmos! Trata-se daquilo queo homem mais ignora no mundo, quer dizer, o homem (Conforme conferência proferida por Delsarte à Escola Real de Medicina em 1867 in Porte, 1992, p. 233).

É assim que François Delsarte nos apresenta o corpo humano, como expressão poética da criação celestial, como obra de arte viva. François Delsarte, alquimista do gesto, observou, com a racionalidade científica do século em que viveu, os resultados da educação burguesa, fundamentada na dissimulação e convenção do gesto advindas da sociedade de corte. O gesto, expressão máxima da vontade divina, como diria Delsarte, afastara-se de sua natureza, sendo orientado pela medida, pela utilidade, pela economia de energia, traços marcantes de uma sociedade industrial e obtusa que se desenvolvia.

Ora, o que podemos concluir sobre a ascensão destes movimentos entre aqueles constituídos como nobres? Devemos acusá-los indiscriminadamente de falsidade? Aqui poderei, de imediato e sem hesitar, responder com afirmação: sim, todos os nobres mentem! O ambiente onde eles vivem, denominado belo mundo, é uma perpétua mentira (Delsarte apud Randi, La teoría delsartiana del gesto in Randi, 1993, p. 57).

Delsarte não observou o corpo espetacular, ao contrário, elegeu o corpo ordinário como centro de suas reflexões poéticofilosóficas. Observou os corpos que vagavam ordenados pelas ruas de uma cidade modelar, Paris. Observou também os operários-máquina nas fábricas, os corpos moribundos nos leitos hospitalares, as crianças brincando nos parques, os gestos que compunham salões burgueses e festas populares. Observou, enfim, corpos "fabricados" por uma sociedade recém-inaugurada, naufragados na economia e inexpressividade de um corpo morto.

No conjunto de seus manuscritos inacabados e não publicados, Delsarte não faz qualquer alusão ao mundo fantástico do circo - influenciado, talvez, pela concepção elaborada pelos "cientistas" do corpo, em sua grande maioria médicos, militares, pedagogos, filantropos. O balé no auge do romantismo, outro possível local para análise do gesto, também não aparece em suas investigações.

De uma forma muito particular, o balé também se estruturou como uma pedagogia dos corpos retos e virtuosos, tal qual a

Movimento, Porto Alegre, v. 11, n. 2, p.75-88, maio/agosto de 2005 
ginástica científica. Arte e ciência, regidas por normas rígidas e regras previamente fixadas, dirigiam essas formas de educação do corpo.

Delsarte influenciou uma geração de "pedagogos do corpo" nos Estados Unidos ${ }^{2}$ e na Europa no final do século XIX e nas primeiras décadas do século XX, e é, inequivocamente, o tênue fio que conduziu a experiência e o pensamento moderno sobre a dança. Sua teoria foi tomada, com maior ou menor rigor, por diversas áreas do conhecimento, como o teatro, a retórica, a ginástica e a Educação Física.

Evoquemos agora a figura de Jean-Georges Noverre (17271810) para iluminar nossos pensamentos sobre as origens esparsas do corpo como expressão poética. Noverre deixou-nos belas cartas, registros das preocupações de um poeta com os descaminhos de sua arte, o balé. Em sua compreensão, o rápido avanço técnico da arte do balé desviara criadores e intérpretes do verdadeiro sentido da arte: comover. Já no século XVIII, ainda antes de Delsarte, Noverre inquietava-se com a maquinização dos gestos e do próprio corpo do bailarino. O corpo, matéria da criação em dança, não poderia ser subjugado pela técnica. A técnica é apenas um modo mais racional de intervenção poética, é apenas uma ferramenta a ser incorporada durante a formação do artista, não podendo jamais substituir a capacidade de transcriação do intérprete. Ela amplia possibilidades de intervenção poética permitindo ao artesão do corpo uma maior liberdade de expressão. Ao final da concepção, o virtuosismo técnico, bem como a força física, devem ser colocados de lado. Não é o corpo que se vê, mas a ilusão que ele projeta em si mesmo. Noverre, como seus contemporâneos poetas, questiona a estrutura envelhecida de uma sociedade aristocrática. Sigamos com a leitura de alguns trechos destas famosas cartas editadas pela primeira vez em 1760

sobre a expressividade do corpo, revelada pela tríade voz-palavra-gesto (emoçãopensamento-vontade). Sobre a obra de François Delsarte consultar: PORTE, François De/sarte: une anthologie (1992); RANDI (org.), François De/sarte: le legge del teatro (1993); MADUREIRA, François Delsarte: personagem de uma dança (re) descoberta (2002); entre outros.

2 Steele MacKaye (1842-1894) foi o responsável pela divulgação do pensamento delsarteano nos Estados Unidos. Inicialmente MacKaye levou os ensinamentos de seu mestre, com quem trabalhou no período mais maduro de sua obra, para as artes dramáticas, mas rapidamente estas teorias foram tomadas pela ginástica e pela educação moral e física. Mackaye desenvolveu um treinamento físicoexpressivo para o ator denominado Ginástica Harmônica. Foi através de um encontro entre MacKaye e Ted Shawn (1891-1972) que a teoria delsarteana pôd

Movimento, Porto Alegre, v. 11, n. 2, p.75-88, maio/agosto de 2005 
Os passos, o desembaraço, o brilhantismo dos encadeamentos, o aprumo, a firmeza, a velocidade, a leveza, a precisão, as oposições de braços e pernas, eis o que chamo de omecanismo da dança; quando todas estas partes não se põem em marcha impulsionadas pelo espírito, quando o engenho deixa de dirigir todos os movimentos, quando o sentimento e a expressão não lhes emprestam as forças capazes de me emocionar e de me interessar, então aplaudo a destreza, admiro o homem-máquina, faço justiça à sua força, à sua agilidade; mas ele não me provoca nenhuma agitação, não me enternece, não me causa mais sensação que um arranjo de palavras como este: vem... do... vergonha... jamais... a.. crime... e... cadafalso... do. No entanto, essas palavras arranjadas por um grande homem compõem o belo verso do conde d'Essex: "A vergonha vem docrime jamais do cadafalso". Dessa comparação é preciso concluir que a dança contém em si mesma tudo o que é necessário a uma linguagem nobre. Para isso não é suficiente conhecer-lhe oalfabeto. Quealgum homem de gênio combine as letras, forme e ligue as palavras: ela cessará então de ser muda e falará com força e energia e, assim, os balés partilharão com as melhores peças de teatro a glória de tocar, enternecer, fazer correr lágrimas, além de divertir, seduzir e agradar, nos gêneros menos sérios. A dança, embelezada pelo sentimento e conduzida pelo engenho, receberá enfim, junto com os aplausos e elogios que toda a Europa dedica à poesia eà pintura, as recompensas com que também as honramos (Noverre, carta 2, in Monteiro, 1998, p. 197-198).

A pintura e a dança têm essa vantagem sobre as outras artes: a de ser de todos os países, de todas as nações. Linguagens universalmente compreendidas, em toda parte causam igual sensação. Se nossa arte ainda que imperfeita seduz e cativa o espectador; se por vezes, mesmo desprovida dos encantos da expressão, perturba, emociona e lança nossa alma em agradável desordem, qual não seria sua força, seu império sobre nossos sentidos, se os seus movimentos fossem dirigidos pelo espírito e seus quadros, esboçados pelo sentimento! Não há dúvida de que os balés serão preferidos à pintura quando aqueles que os executam forem menos autômatos e aqueles que os compõem mais bem preparados [...] A dança precisa apenas de um bom modelo, de um só homem de gênio, e os balés mudarão de caráter. Apareça, pois, esse reformador da verdadeira dança, reformador do gosto falso e dos hábitos viciosos que empobreceram a arte, mas que apareça na capital. Se quiser persuadir, que abra os olhos por demais fascinados dos jovens bailarinos, que diga a eles: Filhos de Terpsícore, renunciai às cabriolas, aos entrechats e aos passos muito complicados, abandonai os trejeitos para entregar-vos aos sentimentos, à graça ingênua e à expressão. Dedicai-vos à pantomima nobre; não esqueçais jamais que ela é a alma de vossa arte. Colocai espírito e raciocínio em vossos pas de deux, para que a volúpia lhes caracterize o andamento e o engenho e proceda à distribuição de todas as situações. Abandonai essas máscaras frias, cópias imperfeitas da natureza; elas ocultam vossos traços, eclipsam, por assim dizer, vossa alma e vos privam da parte mais necessária à expressão. Desfazei-vos das perucas enormes e dos penteados gigantescos, que fazem com que a cabeça perca a justa proporção que deve ter em relação ao corpo. Libertai-vos das anquinhas rígidas e armadas, que privam a atuação de seus encantos, que desfiguram a elegância das posturas e apagam a beleza de contornos que o busto deve ter em suas diversas posições (Noverre, carta 4, in Monteiro, 1998, p. 211-212).

Movimento, Porto Alegre, v. 11, n. 2, p.75-88, maio/agosto de 2005 
Seguindo esta mesma tradição da busca de um corpo ressignificado pela experiência poética, Delsarte desenvolve a noção do gesto como uma linguagem. Tal qual Noverre, Delsarte fundamenta seu pensamento da força e universalidade da linguagem silenciosa do gesto: "Pois o corpo do homem, este diamante da criação, é o alfabeto universal da enciclopédia divina" (Delsarte in Porte, 1992, p. 26).

Pensemos um pouco sobre a linguagem. A arte é uma forma de linguagem, mas uma linguagem, de certa forma, estrangeira. Louise Bourgeois nos ilumina com sua escultura de palavras: "A arte é uma língua, uma língua chinesa" (2000, p. 131). A linguagem compõe vastos territórios que seguem inexplorados. É absolutamente infrutífero percorrer as infinitas paisagens de uma língua por estradas seguras. Mais vantajoso - e igualmente mais arriscado - é deixar-se perder. Para se conhecer os contornos de uma língua não basta memorizar estruturas gramaticais e combiná-las como num jogo infantil. É preciso encarnar seu mitos, decifrar seus enigmas e entoar suas dissonâncias. As línguas, encerradas numa natureza ambígua e contraditória, raramente comunicam sentidos inequívocos. Ademais, "os símbolos formam uma língua, mas não aquela que você imagina conhecer [...] Não existe linguagem sem engano" (Calvino, 1990, p. 48). Enganando-se, a linguagem multiplica potencialidades de expressão e revigora a história das palavras, dos gestos e olhares esquecidos.

Não é apenas nas obras canônicas que podemos fruir do fascínio da linguagem. Podemos descobrir tesouros inestimáveis na presença viva de um narrador ou mesmo na oralidade volátil das conversações cotidianas.

Particularmente, porém, eu quero, para permanecer mais naquilo que nos interessa nesse momento, fornecer ao intérprete de obras escritas o conselho urgente de exercitar com zelo a interpretação das conversações significativas. Pois, a presença imediata do falante, a expressão viva que manifesta a participação de todo o seu ser espiritual, a maneira como ali os pensamentos se desenvolvem a partir da vida em comum, tudo isto estimula, muito mais do que o exame solitário de um texto inteiramente isolado, a compreender uma seqüência de pensamentos, simultaneamente como um momento da vida que irrompe e como uma ação conectada com muitas outras, mesmo aquelas de gêneros diferentes (Schleiermacher, 1999, p. 34).

"Deonde vem a história que o senhor me contou recentemente?" pediu afinal. "de um livro?" "Sim" - respondi com tristeza, "os eruditos a enterraram nele, desde que morreu; isso não faz muito tempo. Há cem anos ela ainda estava viva, certamente despreocupada, em muitos lábios. Mas as palavras que os homens

Movimento, Porto Alegre, v. 11, n. 2, p.75-88, maio/agosto de 2005 
usam agora, essas palavras pesadas, não cantáveis, eram inimigas da história e tiraram dela uma boca após a outra, de tal modo que no fim ela vivia só em uns poucos lábios secos, muito retirada e pobre, como em parcos pertences de viúva. Ali morreu, sem deixar descendentes, e comoera previsível foi sepultada com todas as honras em um livro, onde outras de sua espéciejá se encontravam." "E quantos anos ela tinha quando morreu?" perguntou meu amigo, entrando em consonância comigo. "Entre 400 e 500 anos," informei a verdade, "várias de suas parentes atingiram idades incomparavelmente superiores." "Como, sem nunca descansarem num livro?" espantou-se Ewald. Esclareci: "Atéonde sei, elas apenas viajavam de um lábio a outro." "E nunca dormiam?" "Claro, elevando-se da boca do cantor, de vez em quando permaneciam em um coração, onde era quente e escuro." "Os homens eram tão calmos que os cantos podiam dormir em seus corações?" Ewald me parecia bastante descrente. "Deve ter sido assim. Afirmam que eles falavam menos, dançando danças que se animavam gradativamente, com algo que entorpecia, e sobretudo: não gargalhavam, como se pode ouvir hoje com freqüência, apesar da elevada cultura geral." (Rilke, 1998, p. 31-32).

Como será que poderíamos "traduzir" os pensamentos esvoaçantes presentes na brevidade de um gesto ou de um olhar? Como poderíamos compreender as entrelinhas da linguagem silenciosa do gesto? É justamente nesse território que Delsarte elaborou sua obra.

Aquilo que constitui a debilidade da linguagem articulada, da linguagem filosófica, ésua sucessividade; necessita enunciar frase por frase; cada fraseéconstituída por um certo número de palavras, de vogais, de consoantes, e não tem fim... quantas coisas precisam ser escritas para exprimir um sentimento? Um volume não bastaria, no entanto um gesto apenas é capaz de dizê-lo. É preciso escrever um volume inteiro para traduzir as coisas que existem num único gesto. Este volume não poderia expressar o que um singelo movimento poderia fazê-lo, pois um singelo movimento expressa todo o meu ser. Toda inteireza do homem se expressano gesto, por isso o gestoé persuasivo, éo agente direto da alma, diz sobre tudo (Delsarte apud Porte, François Delsarte: il movimento e il gesto in Randi, 1993, p. 45-46).

O livro sagrado compreende a verdade de que o silêncio é a palavra de Deus. De fato, caros senhores, o silêncio não é a eloqüente expressão da alma? Será que um homem apaixonado constrói frases? Será que diante do objeto contemplado, um olhar ou um toque das mãos não revela ao homem apaixonado mil vezes mais do que um discurso, ainda que fosse um discurso elaborado pela academia? (Conforme conferência proferida por Delsarte à Escola Real de Medicina em 1867 in Porte, 1992, p. 236-237).

Emile Jaques-Dalcroze ${ }^{3}$ também pensou numa possível educação poética do corpo e de sua linguagem. Fragmentos de sua

François Delsarte (1963).

3 Emile Henri Jaques nasceu na terra da música, em Viena, Áustria, no ano de 1865. Seus pais eram suíços e logo retornaram ao país de origem. Dalcroze, nome

Movimento, Porto Alegre, v. 11, n. 2, p.75-88, maio/agosto de 2005 
obra são encontrados nas pedagogias do corpo que vigoraram desde o início do século XX. O pensamento de Dalcroze influenciou não apenas a prática pedagógica da música e da dança; a denominada ginástica moderna ${ }^{4}$ apoiou-se nas primeiras idéias por ele lançadas no que concerne à educação expressiva e rítmica do corpo. Juntamente com Noverre e Delsarte, Dalcroze desenvolveu bases de um pensamento sobre a expressividade do corpo, a Rítmica. Este pensamento pode ser entendido como um conjunto de estudos da plasticidade do corpo como arte. Compreendem uma leitura do movimento, da expressão, do ritmo, da qualidade e da dinâmica dos esforços presentes em cada gesto, retirados da vida cotidiana. De alguma forma esses homens do espetáculo se encontraram, direta ou indiretamente, em composição de forças.

Dalcroze encontrou em sua prática pedagógica todo tipo de dificuldade físico-rítmico-expressiva de seus alunos-musicistas e obrigou-se a encontrar meios de minimizar o que denominava uma arritmia generalizada, uma arritmia da sociedade: "A arritmia musical é conseqüência de uma arritmia de caráter geral" (Dalcroze apud Langlade e Langlade, 1982, p. 62). Problemas de uma educação musical incompleta que se seguiria na vida profissional dos musicistas. A matéria da criação de sua linguagem, o corpo, estava embrutecida, era preciso poetizá-la. Inspirado nas leis de Delsarte, Dalcroze desenvolveu um conjunto de exercícios rítmico-expressivos denominado Plástica Animada.

Pouco se fala sobre Dalcroze como um homem da música e do teatro; porém, sabe-se que ele compôs e dirigiu diversos espetáculos, obras que traduziam a expressão poética do corpo. A Rítmica pode ser tomada como uma experiência poética de educação da sociedade, numa resistência à maquinização da vida.

[...] Um cidadão completo deve ser, ao sair da escola, capaz não apenas de viver normalmente, mas também de sentir com emoção a vida [... ] Diante de toda a excitação que a guerra nos movimenta nesta triste época, é conveniente refletir seriamente sobre o amanhã. Mas uma vez que a guerra termine, nãoénecessário que nossa exaltação venha à tona enem que nos matemos diante da escassez de

criado e adotado profissionalmente por Emile Henri Jaques, estudou música desde criança e dedicou toda a sua vida à criação, ao ensino e à formação de desde criança e dedicou toda a sua vida a criação, ao ensino
musicistas e professores. Morre, em Genebra, no ano de 1950.

4 A idéia de uma educação do ritmo e da expressão através da ginástica fo inicialmente desenvolvida por um aluno de Dalcroze, o alemão Rudolf Bode (1881-1971). Sobre Rudolf Bode e a influência do pensamento dalcroziano na história da ginástica moderna consultar: LANGLADE e LANGLADE, Teoría general de la gimnasia (1982).

Movimento, Porto Alegre, v. 11, n. 2, p.75-88, maio/agosto de 2005 
alimento. Uma educação poética combinada em grande medida com o exercício corporal poderia, sozinha, apaziguar nosso sistema nervoso completamente comprometido. Se a educaçãoé essencialmente esportiva, ela ultrapassará seu objetivo e criará gerações inteiras desprovidas de sensibilidade. É importante que a educação faça caminhar lado a lado o desenvolvimento intelectual e o desenvolvimento físico e parece-me que a Rítmica deve ter neste sentido duplo uma influência muito benéfica (Dalcroze, 1965, p. 95).

Devido a inibições e a restrições advindas do lar, da escola e dos treinamentos corporais, os esportes e os jogos são privilegiados como a única forma de exercício físico. O corpo adulto, de uma pessoa comum, do mundo ocidental de hoje, é incapaz de produzir a pura sucessão da vontade. Esta é uma das razões pelas quais Steele MacKaye criou a Ginástica Harmônica, com a aprovação de Delsarte, no sentido de treinar e disciplinar o corpo que se tornaria um responsável e sério instrumento através do qual cada movimento fluido poderia circular sem os obstáculos da dureza e inflexibilidade das articulações emúsculos (Shawn, 1963, p. 49-50).

\section{Arte e Educação Física: possibilidades de com- posição}

A ginástica esteve muito próxima da arte e por ela foi constituída em concepções não hegemônicas e quase sempre ocultadas pelas várias histórias escritas da ginástica e mesmo da Educação Física. Parece que a arte era portadora de signos que retiravam uma certa objetividade daquilo que se desejava criar com o nome de Ginástica e mais tarde de Educação Física. Os corpos cênicos e expressivos da arte, sempre no plural, não poderiam traduzir a concepção posta de forma hegemônica pelo pensamento da ginástica de um corpo único, de padrões únicos de referência, de pensar "o corpo" e não corpos.

Parece que o corpo na arte é sempre contaminado pelas profundezas da alma humana, escuras, misteriosas e singulares. Parece que o corpo da Ginástica e da Educação Física se tornou um simulacro limpo e acabado, fechado e explicado a partir da ciência como forma hegemônica de conhecimento. No entanto, é possível falar da relação entre ciência e arte e pensar estes campos não como oposição, mas como complementaridade.

Talvez o diálogo com a arte, por ser ela uma forma de conhecimento do mundo, de apropriação diferenciada da realidade, revele a evidência dos muitos corpos existentes no Brasil, dada a diversidade de etnias, portanto de culturas, de modos de vida, hábitos e conhecimentos que o formaram. A arte sempre

Movimento, Porto Alegre, v. 11, n. 2, p.75-88, maio/agosto de 2005 
foi capaz de mostrar as ambigüidades, os paradoxos, a diversidade (Soares e Silva, 2003).

Esta composição entre a arte e a Educação Física é muito desejada, mas existiriam riscos nesta aproximação? Não é improvável que a dança, por exemplo, seja encarada como mera "atividade física" e, como tal, passe a ser tratada a partir de parâmetros ditados pelos programas de treinamento esportivo de alto rendimento, ou mesmo regulamentada a partir de paradigmas médicos de higiene e saúde. Esta realidade, de fato, alastra-se no campo da dança e de outros espaços de festa e de celebração da vida.

A dança, como o circo e a capoeira, não se pretende como mera atividade física ou como compensação de uma jornada de trabalho extenuante. A dança como expressão poética do corpo é uma experiência única, pessoal e subjetiva, não atende às demandas da produtividade. Ela é uma experiência da beleza onde os corpos são múltiplos, conscientes da própria materialidade e sensíveis à expressividade do outro.

Se um homem, sem nenhum esforço de sua parte, experimentar, ao ler, ver ou ouvir a obra de outro homem, uma emoção que o una aquele homem e a outros homens que estejam, como ele, percebendo uma obra de arte, eis que se trata de uma verdadeira obra de arte. Por mais que seja poética, semelhante à verdadeira, por mais que produza impacto ou interesse, ela não será uma obra de arte se não suscitar no indivíduo aquele sentimento de alegria, completamente diferente de qualquer outro (Tolstoi, 1994, p. 119).

Mas também creio que chorava porque, através da música, adivinhava talvez que havia outros modos de sentir, havia existências mais delicadas e até com um certo luxo de alma (Lispector, 1977, p. 60).

A incorporação da arte nas reflexões concernentes à Educação Física poderia auxiliar na configuração de uma outra lógica para pensar o corpo e todos os fenômenos a ele ligados, inclusive no que diz respeito a sua expressão gestual. Pensar a arte como forma de conhecimento talvez permitisse superar dicotomias clássicas presentes no modo de conceber e pensar o corpo. "A arte é sempre uma revelação, um desejo transitório de apreender, intuitivamente e de uma só vez, todas as leis deste mundo - sua beleza e sua feiúra, sua humanidade e sua crueldade, seu caráter infinito e suas limitações" (Tarkoviski, 1990, p. 39-40).

A arte, portanto, propõe uma outra forma de conhecer o mundo, de compreender e incorporar a multiplicidade com a

Movimento, Porto Alegre, v. 11, n. 2, p.75-88, maio/agosto de 2005 
qual se constrói o conhecimento, sua transitoriedade, fragilidade, precariedade. Propõe ainda o rompimento com as clássicas oposições que se construíram e, ao mesmo tempo, a relativização do valor que atribuímos às diferentes formas de conhecer.

Afinal, é possível pensar numa composição entre arte e Educação Física? Insistimos na noção de composição (Sant'Anna, 2001, p. 94-95) como contraponto de uma certa forma de apropriação dos saberes do mundo. Tal qual os "cientistas do corpo" no século XIX, observamos sucessivas investidas políticas de um controle absoluto dos saberes do corpo, como se fosse possível capturar as infinitas camadas que recobrem os sentidos múltiplos e milenares das práticas corporais. Sigamos a histórica composição entre as artes. Todas as artes são irmãs. Todo artista compõe inspirado numa obra de outro, e ele nos deixa fortes indícios de seu empréstimo. O cinema revive a pintura, a pintura desenha os rostos da literatura, a dança movimenta a escultura, e assim as artes, traduzindo-se mutuamente, percorrem uma viagem ao redor do mundo. Pensemos nas seguintes indagações absolutamente pertinentes:

Se as práticas corporais representam um profundo culto ao corpo elevam a uma acentuação do narcisismo, até que ponto essas práticas devem ser incentivadas? Se o narcisismoleva a uma permanente insatisfação, na medida que as experiências com o mundo são desvalorizadas frente a um ego exacerbado, estariam essas práticas corporais, em última análise, prestando um desserviço aos indivíduos que as procuram? Se há culto ao corpo, baseado na busca por um modelo hegemônico de beleza, queérealizado de forma irrefletida, não se está incentivando, ainda mais, a perda de autonomia do sujeito? (Silva, 1996, p. 250)

A Educação Física é um espaço de composição, como tentamos mostrar ao longo deste texto. Ela ocupa uma posição de grande responsabilidade, regendo e orientando os usos e abusos do corpo. A Educação Física como educação poética do corpo pode configurar uma resistência contra o esvaziamento de sentido das práticas corporais e o desejo, sempre perigoso, dos pensamentos únicos que desfiguram a experiência subjetiva e sensível.

Movimento, Porto Alegre, v. 11, n. 2, p.75-88, maio/agosto de 2005 
Physical education, language and art: possibilities of a poetic dialog of the body

Abstract: Is it possible to consider a harmonic composition

among Physical Education, language and art? The incorporation of an artistical reflection to physical education provides another approach to understand body and all the phenomena connected to it, including its gestural expression. Some discussions are presented in this article regarding historical aspects of this relation, based on the studies carried out by Noverre, Delsarte and Dalcroze.

Keywords: education, language, art, phisycal education, body, expression.

\section{Educación física, lenguage y arte: \\ posibilidades de un diálogo poético del cuerpo}

Resumen: ¿Es posible pensar una composición entre Educación Física, lenguaje y arte? La incorporación del arte en las reflexiones sobre Educación Física podría ayudar a generar una lógica diferente para pensar el cuerpo y todos los fenómenos ligados a él, incluso en su expresión gestual. En este artículo presentamos algunas discusiones sobre la historicidad de esta relación, tomando como base los estudios de Noverre, Delsarte y Dalcroze.

Palabras-clave: educación, lenguaje, arte, educación física, cuerpo, expresión.

\section{Referências}

BACHELARD, Gaston. O ar e os sonhos. São Paulo: Martins Fontes, 1990.

BAUDELAIRE, Charles. Escritos sobre arte. São Paulo: Edusp, 1991.

BOURGEOIS, Louise. Destruição do Pai/Reconstrução do Pai. São Paulo: Cosac \& Naify, 2000.

CALVINO, Italo. As cidades invisíveis. São Paulo: Cia. das Letras, 1990.

DALCROZE, Emile Jacques. Le rythme, la musique et l'éducation. Suíça: Edition Fœtisch, 1965

LANGLADE, Alberto;LANGLADE, Nelly Rey de. Teoría general de la gimnásia. 2. ed. Buenos Aires: Stadium, 1982.

Movimento, Porto Alegre, v. 11, n. 2, p.75-88, maio/agosto de 2005 
LISPECTOR, Clarice. A hora da estrela. 7. ed. Rio de Janeiro: Nova Fronteira, 1977.

MADUREIRA, José Rafael. François Delsarte: personagem de uma dança (re) descoberta. Dissertação. Campinas: Faculdade de Educação da UNICAMP, 2002.

MONTEIRO, Marianna. Noverre: cartas sobre a dança. São Paulo: Edusp, 1998.

PASOLINI, Pier-Paolo. Os jovens infelizes. São Paulo: Brasiliense, 1990.

PORTE, Alain. François Delsarte: une anthologie. Paris: IPMC, 1992.

RANDI, Elena (org.) François Delsarte: le legge del teatro - I/ pensiero scenico del precursore della danza moderna. Roma: Bulzoni, 1993.

RILKE, Rainer Maria. Histórias do Bom Deus. Rio de Janeiro: Sette Letras, 1998.

SANT'ANNA, Denise Bernuzzi de. Corpos de passagem: ensaio sobre a subjetividade contemporânea. São Paulo: Estação Liberdade, 2001.

SCHLEIERMACHER, Friedrich. Hermenêutica: Arte e Técnica da Interpretação. Petrópolis: Vozes, 1999.

SHAWN, Ted. Every little movement: a book about François Delsarte. 2. ed. New York: M. Witmark \& Sons, 1963.

SILVA, Ana Márcia. Das práticas corporais ou porque "narciso" se exercita. Revista Brasileira de Ciências do Esporte, Florianópolis; v. 3, n. 17, p. 244-251, maio 1996.

SOARES, Carmen Lúcia; SILVA, Ana Márcia. Corpos de um Brasil multicultural: diálogos entre arte e ciência. Revista Iberoamericana, Berlim; n. 10, p. 127142, jun. 2003.

SOARES, Carmen Lúcia. Imagens da educação no corpo: estudo a partir da ginástica francesa no século XIX. 2a ${ }^{a}$. ed. Campinas: Autores Associados, 2002. TARKOVISK, Andrei. Esculpir o tempo. São Paulo: Martins Fontes, 1990.

TOLSTOI, Leon. O que é a arte? São Paulo: Experimento, 1994.

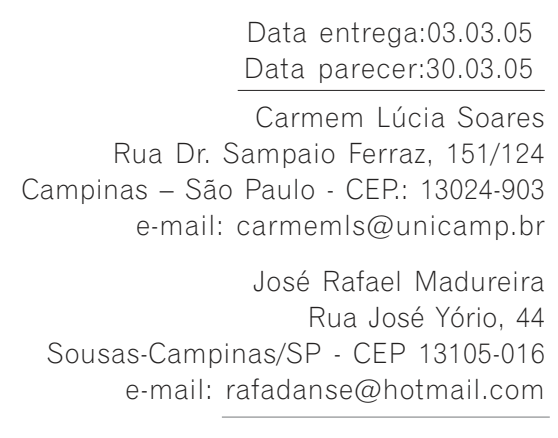

Movimento, Porto Alegre, v. 11, n. 2, p.75-88, maio/agosto de 2005 